\title{
Evaluating the Origin of Arterial in Ectopic Kidneys: About 4 Cases
}

Hounton $\mathrm{SED}^{1,2}$, Laleye $\mathrm{CM}^{2,3^{*}}$, Hadonou $\mathrm{AA}^{2,4}$, Agossou $\mathrm{C}^{1,2}$, Videgla $\mathrm{BL}^{1,2}$, Baglo $\mathrm{AKM}^{1}$, Lokossou $\mathrm{AL}^{1}$, Adjadohoun $\mathrm{SM}^{1}$, Yekpe $\mathrm{AP}^{1}$, Hounnou $\mathrm{GM}^{2}$, Biaou $\mathrm{O}^{1}$, Agossou-Voyeme $\mathrm{AK}^{2}$

${ }^{1}$ Medical Imaging Department of CNHU-HKM Cotonou, Benin

${ }^{2}$ Laboratory of Human Anatomy of the Faculty of Health Sciences (FSS) of Cotonou, Benin

${ }^{3}$ Visceral Surgery Department of CNHU-HKM Cotonou, Benin

${ }^{4}$ Surgery Department of the Departmental University Hospital of Borgou, Benin

DOI: $10.36348 /$ sijap.2020.v03i07.002

| Received: 18.07.2020 | Accepted: 25.07.2020 | Published: 28.07.2020

*Corresponding author: Laleye Christel Marie

\section{Abstract}

Objective: To Study 4 cases of vascular anatomy of ectopic kidneys about. Clinical cases: The first case is marked by two pelvic kidneys vascularized by an artery of homolateral iliac origin, of which that of the right gives two branches to the left kidney. The second case found a right iliac kidney vascularized mainly by a renal artery from the contralateral common iliac and two accessory arteries, one from the abdominal aorta and the other from the ipsilateral common iliac. The third case, note two iliac kidneys including that of the right received its vascularization of the abdominal aorta by two arteries and that of the left received his of the common iliac ipsilateral, abdominal aorta and one of the arteries right renal. The fourth case, is a right iliac kidney receiving its vascularization of the aorta by two arteries and contralateral common iliac by a branch. Message to remember: The arterial vasculature of the ectopic kidney originates at the level at which the migration stopped. Given the variability in the number, origin, route and termination of ectopic kidney arteries, it is important to know them for the adequate management of renal vascular diseases, especially the renal artery interventional and follow-up. renal transplantation.

Keywords: ectopic kidney, arterial vascular anatomy, abdominal aorta, common iliac artery.

Copyright @ 2020: This is an open-access article distributed under the terms of the Creative Commons Attribution license which permits unrestricted use, distribution, and reproduction in any medium for non-commercial use (NonCommercial, or CC-BY-NC) provided the original author and source are credited.

\section{INTRODUCTION}

Renal ectopia results from a failure to ascend the metanephros of the pelvis to the abdominal stage in its box during embryogenesis [1]. It is found approximately once in 1000 births [2]. Thus the modal arterial vasculature of these ectopic kidneys is modified. We were interested in arterial vascular anatomy of ectopic kidneys, about 4 cases found on the CNHU-HKM scanner.

\section{CLINICAL CASES}

\section{Case 1}

This is a 12-year-old Sickle cell patient who underwent abdominal (CT) angiography and pelvic limbs for a vascular mass of the right femoral trigon found on ultrasound in a context of sepsis. CT angiography found: a right aneurysm of the right femoral artery, two pelvic kidneys juxtaposed at the ventral hilum whose arterial vasculature is described as follows (Figure 1):

- On the right, there is a renal artery arising from the ipsilateral common iliac artery (at 1 $\mathrm{cm}$ from the aortic bifurcation at L4), with a caliber of $7 \mathrm{~mm}$. After a short $1.5 \mathrm{~cm}$ descending, it gives 3 branches exclusively for the right kidney approaching the cortex. In addition, it also gives an accessory branch to the left kidney approaching it by its hilum and a common trunk which is divided for the two kidneys approaching them by the hilum.

- On the left, there is a renal artery arising from the ipsilateral common iliac artery (at $4 \mathrm{~mm}$ from the aortic bifurcation at L4), with a caliber of $2 \mathrm{~mm}$, after a path of $1 \mathrm{~mm}$, gives a polar collateral superior then laterally bypasses the kidney to join the renal hile oriented strictly forward. 

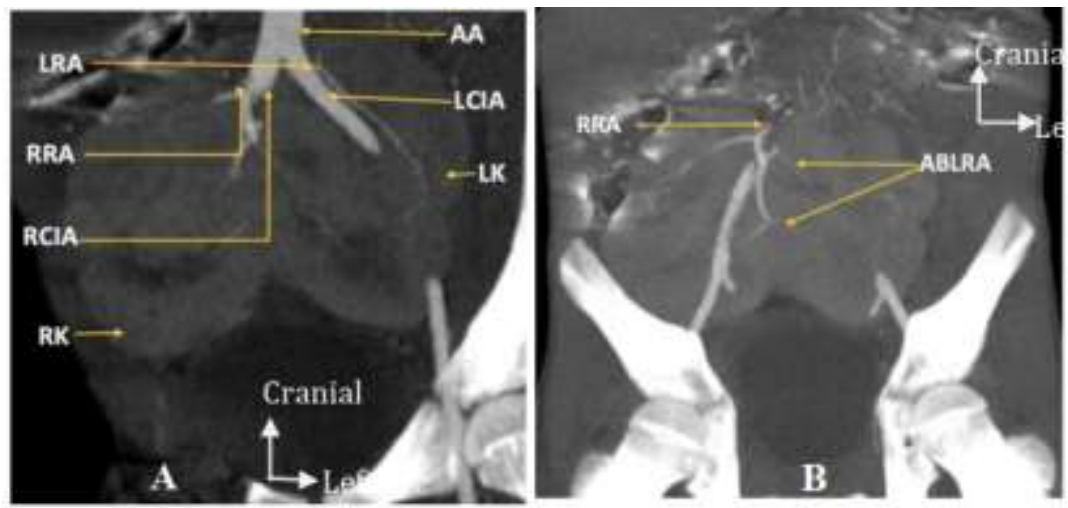

Fig 1A and 1B: Frontal reconstruction with maximum intensity project (MIP): AA: abdominal aorta, LCIA: left common iliac artery, LK: left kidney, LRA: left renal artery, RRA: right renal artery, RCIA: right common iliac artery, RK: right kidney, ABLRA: arterial branches from the right renal artery to the left

\section{Case 2}

This is a 74-year-old male patient in whom an injected abdominopelvic CT scan was performed for the exploration of a right iliac ectopic right to medial hile accidentally discovered on ultrasound.

The right iliac ectopic kidney receives a main renal artery and two accessories (upper and lower). The main one (Figure 2A) is born from the contralateral common iliac artery $9 \mathrm{~mm}$ from the aortic bifurcation with a caliber of $7 \mathrm{~mm}$ at the origin and then joins the renal hile after a short course in italic $S$ of $4 \mathrm{~cm}$ to give two branches. middle and lower terminals. The lower accessory (Figure 2B) from the right common iliac with a caliber of $2 \mathrm{~mm}$ and a descending path, approaches the upper half of the kidney back by its cortex. The superior accessory or superior polar (Figure 2C), is born from the ventral side of the abdominal aorta $1.5 \mathrm{~cm}$ from the aortic bifurcation, with a caliber of $3 \mathrm{~mm}$. After a winding path approaches the kidney through its cortex to the upper pole.
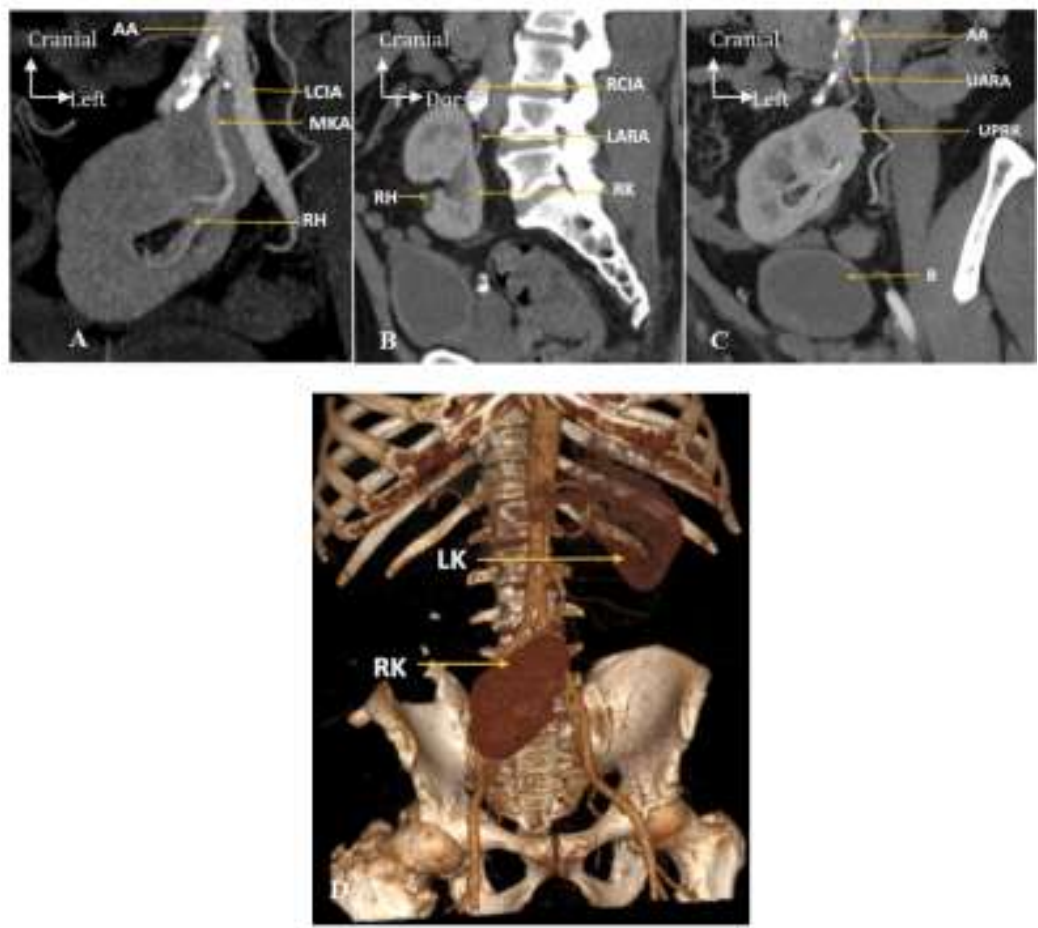

Fig-2: A- Frontal reconstruction with MIP (maximum intensity project), B- Sagittal reconstruction with minip (minimum intensity project), Coblique frontal reconstruction with minip (minimum intensity project) D- 3D reconstruction in volume rendering showing the two kidneys AA : abdominal aorta,UARA : upperaccessoryrenalartery, UPRK : upper pole of the right kidney, B : bladder, LCIA : left common iliac artery, MKA : main kidneyartery, RH: rénalhil, RCIA: right commoniliacartery, LARA : lower accessory renal artery, RK : right kidney, LK : leftkidney

\section{Case 3}

24-year-old patient, received on ultrasound for abdominal pain, in whom two iliac kidneys were found in hile oriented forward. An angioscanner wasperformed offline for the study of arterial vascularization of the kidneys. The right kidney receives three arteries of which two of the same caliber almost $(5 \mathrm{~mm}$ for the upper and $6 \mathrm{~mm}$ for the lower) 
from the abdominal aorta and a lower polar (Figure 3B) of $2 \mathrm{~mm}$ caliber from the artery ipsilateral common iliac at $5 \mathrm{~cm}$ from the aortic bifurcation (Figure $3 \mathrm{~A}$ ). The superior renal artery, $2 \mathrm{~cm}$ long, is born $2 \mathrm{~cm}$ from the aortic bifurcation of the lateral flank of the aorta and is carried almost horizontally towards the kidney. The inferior renal artery, $4 \mathrm{~cm}$ long, is $8 \mathrm{~mm}$ from the aortic bifurcation and has a pre-aortic descending path and then bends towards the kidney. It gives a branch to the contralateral kidney (Figure 3E). These different arteries approach the kidney through its cortex. The left kidney (Figure 3C, 3D and 3E) is irrigated by three arteries: one from the ipsilateral common iliac just after birth, $3 \mathrm{~cm}$ long with a caliber of $4 \mathrm{~mm}$ is worn down and out and then approaches the kidney by the cortex at the upper pole. Another, arising from the ventral side of the abdominal aorta $1 \mathrm{~cm}$ from the bifurcation, goes out along the left common iliac artery and ends in the kidney laterally through the cortex. The third artery is a branch of the right inferior renal artery that penetrates the kidney through the hile.

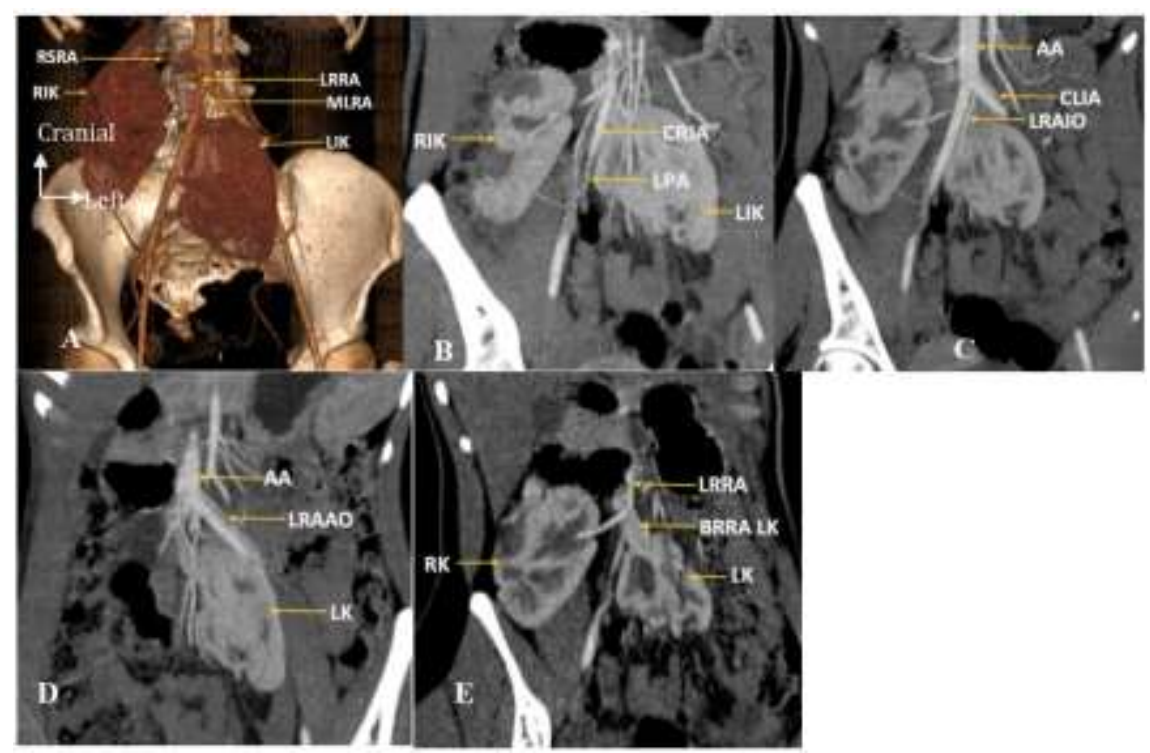

Fig-3: A- 3D rendering in volume rendition; B, C, D, C: Oblique frontal reconstruction with minIP (minimum intensity project). RSRA: right superiorrenalartery, RIK: right iliackidney, LRRA: lower right renalartery, MLRA: main leftrenalartery, LIK: leftiliackidney, LPA: lower polar artery, CRIA: common right iliacartery, AA: abdominal aorta, CLIA: commonleftiliacartery, LRAIO: leftrenalartery of iliacorigin,

LRAAO: leftrenalartery of aorticorigin, RK: right kidney, BRRA: branch of the right renalartery to the leftkidney, LK: leftkidney

Case 4

This is a 15-year-old child, referred by urologists for the study of the vascularization of a right iliac kidney (Figure 4A) in hile oriented medially discovered on ultrasound. The right ectopic kidney is vascularized by three arteries, two of which are major (Figure 4B) and one accessory (Figure 4C). The upper main artery originates from the abdominal aorta $2 \mathrm{~cm}$ from the bifurcation, for a caliber of $4 \mathrm{~mm}$ and then goes down and out to approach the kidney by its upper pole. The inferior main artery, comes from the contralateral common iliac, with a caliber of $4 \mathrm{~mm}$, to 2 $\mathrm{cm}$ of the aortic bifurcation it presents a descending way to penetrate the kidney by its hile. The accessory renal artery arises from the abdominal aorta $7 \mathrm{~mm}$ from the bifurcation for a caliber of $2 \mathrm{~mm}$ with a descending path enters the kidney by its hile.

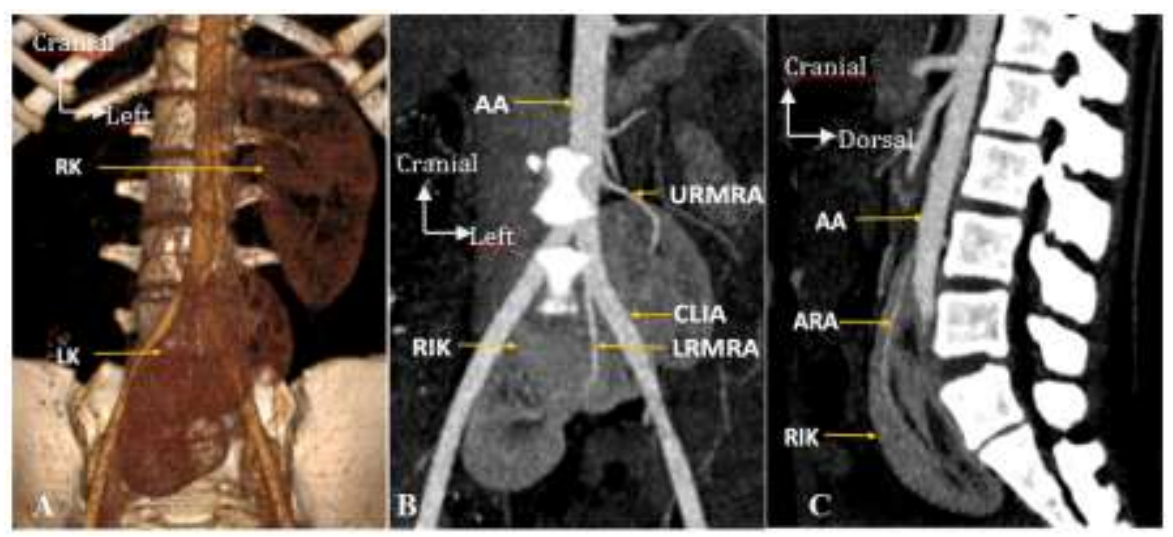

Fig-4: A: 3D rendering in volume rendering, B- oblique frontal reconstruction withminIP (minimum intensityproject), C: Sagittal reconstruction withminIP (minimum intensityproject). RK: right kidney, LK: leftkidney, AA: abdominal aorta, RIK: right iliackidney, URMRA: upper right main renalartery, CLIA: commonleftiliacartery, LRMRA: lower right main renalartery 


\section{DISCUSSION}

The migration of metanephros from the sacred region to L1 occurs from the 6th to the 9th week of development. This migration corresponds in fact to a differential growth of the lumbar and sacral regions, resulting in an unfolding of the lower part of the body of the embryo.

During this "migration", the metanephros successively receives arteries of the aorta at higher and higher levels and involute as the renal ascension progresses, the definitive arteries lying in the lumbar region [3]. According to Felix, there are nine pairs of mesonephric arteries from the dorsal aorta, arranged in skull (1st and 2nd pair), middle (3rd and 4th pair) and caudal (6th to 9th pairs) in fetuses of $18 \mathrm{~mm}$. The renal artery develops from a pair of middle group. The persistence of more than one artery in the middle group leads to the formation of an accessory renal artery [4].

Faced with the migration anomaly of the ectopic kidneys, their arterial vascularization could be understood as an absence of regression of the first arteries nourishing the metanephros during embryogenesis. This is the case in our clinical cases where the ectopic kidneys received multiple arteries of various origin, aortic or iliac common unilateral or contralateral. Several cases have been reported in the literature [5-8]. But this does not explain the cases where the same arterial trunk vascularizes both juxtaposed kidneys. The contiguous nature of the two kidneys would be a hypothesis.

Given the variability in the number, origin, path and termination of ectopic kidney arteries, it is important to know them for adequate management of renal vascular diseases, especially the renal arterial renal arteries including stenosis, renal trauma and kidney transplantation. Multiplex CT angiography plays a very important role in the anatomical study of the ectopic kidney vascularization.

In contexts of fortuitous discovery of renal ectopia, one must not forget the search for a history of renal transplantation so as not to confuse the transplanted kidney with an ectopic kidney.

\section{CONCLUSION}

Kidney ectopia is most often incidental discovery. The arterial vasculature of the ectopic kidney originates at the level at which the migration stopped. These arteries are multiple, of varied aortic or iliac origin and penetrate the kidney either by its hilum or through the renal cortex regardless of the main character or not of the artery.

Acknowledgement: Thanks to OSSENI Razack (PhD Toxicology) for the translation work.

\section{REFERENCE}

1. Sadler T. W., \& Langman, J. (2007). Appareil urogénital in Embryologie médicale. Editions Pradel, $8^{\mathrm{e}}$ édition française, 333.

2. Asghar, M., \& Wazir, F. (2008). Prevalence of renal ectopia by diagnostic imaging. Gomal Journal of Medical Sciences, 6(2):72-76.

3. Garcier, J. M., \& Sakka, L. (2015). Traité d'imagerie vasculaire. Chap 29: Radio anatomie des artères rénales. Elsevier Masson, Paris, 328.

4. Felix, W. (1912). Mesonephricarteries (aa. mesonephricae). In: Kiebel F, Mall FP, editors. Manual of humanembryology. Vol. 2. Philadelphia: Lippincott; 820-825.

5. Hazirolan, T., Öz, M., Türkbey, B., Karaosmanoğlu, A. D., Oğuz, B. S., \& Canyiğit, M. (2011). CT angiography of the renal arteries and veins: normal anatomy and variants. DiagnInterv Radiol. 17:67-73.

6. Russa, A. D. (2017). Preperitoneal pelvic kidney: Revisiting the significance of variant anatomy to the clinician of the future. International Journal of Anatomical Variations, 10(2):21-23.

7. Türkvatan, A., Özdemir, M., Cumhur, T., \& Ölçer, T. (2009). Multidetector CT angiography of renal vasculature: normal anatomy and variants. European radiology, 19(1), 236-244.

8. Özkan, U., Oguzkurt, L., Tercan, F., Kizilkilic, O., Koç, Z., \& Koca, N. (2006). Renal artery origins and variations: angiographic evaluation of 855 consecutive patients. Diagnostic and interventional Radiology, 12(4), 183-186. 